\title{
VARIABILIDADE CLIMÁTICA EM FOZ DO IGUAÇU-PR
}

\author{
Matheus Filippi Chiella ${ }^{(a)}$, Leila Limberger ${ }^{(b)}$ \\ (a) Discentedo curso de Graduação em Geografia - UNIOESTE, matheusfchiella@ hotmail.com \\ ${ }^{(b)}$ Docente do Curso de Geografia - UNIOESTE,leila.limberger@unioeste.br
}

\section{Eixo: CLIMATOLOGIA EM DIFERENTES NÍVEIS ESCALARES: MUDANÇAS E VARIABILIDADES}

\begin{abstract}
Resumo
O presente projeto tem por objetivo estudar a variabilidade climática da cidade de Foz do Iguaçu durante o período de 1961 a 2014, procurando identificar as anomalias de precipitação e temperatura e sua associação com a variabilidade da Temperatura da Superfície dos Mares (TSM).A associação com a TSM justifica-se já que os oceanos compõem um importante regulador climático global, sendo que armazenam muita energia e as alterações em sua temperatura podem desencadear variabilidade climática em vários locais do globo, através do processo de teleconexões atmosféricas. Para atingir o objetivo desta pesquisa serão analisados estatisticamente os dados de precipitação obtidos através do sistema ICEA/AER por meio de correlação linear entre a precipitação e índices de TSM. Os resultados indicam associação da precipitação com a região do ENOS.
\end{abstract}

Palavras chave: variabilidade climática; Índices climáticos; teleconexões atmosféricas; Foz do Iguaçu.

\section{Introdução}

Nos dias atuais o clima vem se modificando rapidamente e nesse sentido o estudo do clima é de suma importância para a sociedade já que ele pode influenciar a dinâmica da paisagem, da economia, das cidades, da agricultura e da vida da população.Além disso, os condicionantes climáticos passaram a assumir papel de insumo natural nos processos físicos e econômicos a partir do momento em que a humanidade passou a depender dos elementos naturais para a apropriação de capital (SANT'ANNA NETO, 1998), como mais facilmente identificado no caso da agricultura. Ao contrário do que se espera, portanto,a irregularidade dos fenômenos meteorológicos(ou seja, a variabilidade climática) ocorre com mais frequência do que os assim chamados padrões habituais ou normais.Atualmente, assume-se que a variabilidade climática é inerente ao conceito de clima (AMBRIZZI, 2003; TAVARES, 2001), sendo que este não pode mais ser compreendido como algo linear, mas sim, composto por "altos e baixos".

No caso do Brasil, com ampla distribuição de terras desde o Hemisfério Norte, passando pela região equatorial, tropical e subtropical do Hemisfério Sul, há uma grande diversidade de climas, bem como diversos padrões de circulação geral e diversos padrões de teleconexão com a variabilidade global de Temperatura da Superfície dos Mares (TSM) que definem os tipos climáticos.Um dos principais 
reguladores globais do clima são os oceanos, já que estes ocupam $70 \%$ da superfície do planeta (LIMBERGER, 2015).

Anomalias de precipitação não ocorrem em pontos isolados, mas, normalmente, ocorrem em vastas regiões, como é o caso dos efeitos do fenômeno El Niño (EN), que favorece a diminuição das precipitações no norte/nordeste do Brasil, bem como o aumento das mesmas na região sul.Os índices que representam anomalias ligadas ao El Niño são o Southern Oscillation Index (SOI) que se caracteriza-se por uma "gangorra barométrica" de grande escala observada sobre a bacia do Pacífico Tropical; oMultivariate ENSO Index (MEI), que é um índice produzido com base em seis variáveis observadas sobre a região do Pacífico Tropical: TSM, pressão ao nível do mar, componente zonal e meridional do vento na superfície do mar, temperatura do ar na superfície e cobertura de nuvens. Além disso, conta-se com o OceanicNiño Index (ONI), que é calculadopela média das anomalias da temperatura da superfície do mar numa área do pacífico equatorial centro-leste (NOAA, 2017).

Além do Pacífico, também no Atlântico encontra-se o índice Tropical South Atlantic(TSA), que é um indicador das temperaturas de superfície no Golfo da Guiné;o Tropical North Atlantic(TNA) e o Atlantic Meridional Mode (AMM) que está associado ao gradiente meridional equatorial (NOAA, 2017).

O presente estudo tem por objetivo estudar a variabilidade climática da cidade de Foz do Iguaçu durante o período de 1961 a 2014, procurando identificar as anomalias de precipitação e temperatura e sua associação com a variabilidade da Temperatura da Superfície dos Mares (TSM).Desse modo, a presente pesquisa possibilitará a ampliação do conhecimento da influência dos oceanos na dinâmica climática da região oeste do Paraná, pois apesar de haver estudos sobre a influência da TSM para a grande região Sul da América do Sul, as particularidades regionais não estão totalmente esclarecidas.

\section{Materiais e Métodos}

Os materiais utilizados foram dados dos índices SOI,MEI,NAO,TNA,TSA,AMM,ONI e PDO, retirados do site: <https://www.esrl.noaa.gov/psd/data/climateindice/list/> e dos dados de precipitação de Foz do Iguaçu por meio do sistema ICEA/AER para o período de 1961 a 2014.

O método que foi utilizado para trabalhar com os dados foi o cálculo de correlação linear, e foi feito um cálculo da significância do $\mathrm{r}$ para $\mathrm{p}<0,05$.

\section{Resultados}

Os valores de correlação linear entre precipitação e os índices climáticos que afetam a precipitação na América do Sul estão apresentados na Tabela 1. Verifica-se que os menores valores de correlação 
linear foram registrados para os índices TSA, NAO e TNA, seguidos de PDO, AMM e SOI. Esperavase que o SOI tivesse correlação linear significativa com a precipitação em Foz do Iguaçu, já que a literatura afirma correlação negativa entre o SOI e a chuva na região Sul do Brasil. Mesmo não sendo significativa, a correlação foi negativa, indicando padrão adequado com o visto na literatura.

Tabela 1 - Valores de correlação linear entre índices climáticos e precipitação em Foz do Iguaçu durante o período de 1961 a 2014. Valores significativos estatisticamente estão em vermelho.

\begin{tabular}{c|c|c|c|c|c|c|c}
\hline NAO & SOI & TNA & TSA & AMM & MEI & ONI & PDO \\
\hline $\mathbf{0 , 0 0 4}$ & $\mathbf{- 0 , 0 6 4}$ & $\mathbf{0 , 0 2 0}$ & $\mathbf{- 0 , 0 0 1}$ & $\mathbf{- 0 , 0 4 0}$ & $\mathbf{0 , 1 7 7}$ & $\mathbf{0 , 1 7 9}$ & $\mathbf{0 , 0 2 8}$ \\
& & & & & & & \\
\hline
\end{tabular}

Valores estatisticamente significativos $(\mathrm{p}<0,05)$ para o tamanho da amostra (420 tempos) foram encontrados na correlação linear entre a precipitação em Foz do Iguaçu e os índices MEI e ONI, que são índices ligados aos fenômenos ENOS, porém que consideram mais variáveis do que somente a pressão atmosférica, como é o caso do SOI. Verifica-se, com isso, que o ENOS tem influência na variabilidade da precipitação na área estudada.

\section{Conclusão}

Por meio do cálculo de correlação linear entre a série temporal de precipitação de Foz do Iguaçu para o período de 1961 a 2014 com índices climáticos que identificam anomalias de TSM conclui-se que há uma correlação linear positiva e estatisticamente significativa com os índices MEI e ONI, ambos ligados aos eventos ENOS. Tal resultado corrobora o padrão já indicado na literatura.

O resultado também mostra a importância de mais estudos ligados à TSM para entender melhor a importância dela no clima da região. Cabe, ainda, considerar que em cada porção do território,as configurações espaciais determinadas pela topografia do relevo, cobertura do solo, rede de drenagem também tem sua importância no clima, mas não foram consideradas nesse estudo.

A partir desse resultado a pesquisa terá prosseguimento na identificação de como os padrões de circulação atmosférica são afetados pelo ENOS e como atingem a região de Foz do Iguaçu.

\section{Referências Bibliográficas}

AMBRIZZI, T. El Niño/Oscilação Sul e teleconexões atmosféricas no hemisfério austral. (Tese de Livre Docência). São Paulo: IAG/USP, 2003.

BERLATO, M.A.; FONTANA, D.C. El Niño e La Niña. Porto Alegre: Editora da UFRGS, 2003.

LIMBERGER, L. Variabilidade da vazão de regiões homogêneas da bacia hidrográfica amazônica brasileira: teleconexões com a temperatura da superfície do mar (TSM) de 1976-2010. Tese (Doutorado). FFLCH/USP, São Paulo, BR, 486p. 2015. 
NOAA.Climate Indices: Monthly Atmospheric and Oceanic Time Series. Disponível em <https://www.esrl.noaa.gov/psd/data/climateindices/list/>. Acesso em 01 mar. 2017.

SANT'ANNA NETO. Clima e organização do espaço. Boletim de Geografia Teorética. Vol. 16, p. 119-131, 1998. 